\title{
Could Heat Therapy Be an Effective Treatment for Alzheimer's and Parkinson's Diseases? A Narrative Review
}

\author{
Andrew P. Hunt ${ }^{1,2 *}$, Geoffrey M. Minett ${ }^{1,2}$, Oliver R. Gibson ${ }^{3,4}$, Graham K. Kerr ${ }^{1,2}$ and \\ Ian B. Stewart ${ }^{1,2}$ \\ ${ }^{1}$ School of Exercise and Nutrition Sciences, Faculty of Health, Queensland University of Technology, Brisbane, QLD, \\ Australia, ${ }^{2}$ Institute of Health and Biomedical Innovation, Queensland University of Technology, Brisbane, QLD, Australia, \\ ${ }^{3}$ Centre for Human Performance, Exercise and Rehabilitation, College of Health and Life Sciences, Brunel University \\ London, Uxbridge, United Kingdom, ${ }^{4}$ Division of Sport, Health and Exercise Sciences, Department of Life Sciences, \\ College of Health and Life Sciences, Brunel University London, Uxbridge, United Kingdom
}

\section{OPEN ACCESS}

Edited by: Julien Périard,

University of Canberra, Australia

Reviewed by:

Vienna E. Brunt,

University of Colorado Boulder,

United States

Mohammed Ihsan,

Aspetar Hospital, Qatar

Brett Romano Ely,

Salem State University, United States

*Correspondence:

Andrew P. Hunt

ap.hunt@qut.edu.au

Specialty section:

This article was submitted to

Integrative Physiology,

a section of the journal

Frontiers in Physiology

Received: 09 August 2019 Accepted: 10 December 2019

Published: 10 January 2020

Citation:

Hunt AP, Minett GM, Gibson OR, Kerr GK and Stewart IB (2020) Could

Heat Therapy Be an Effective

Treatment for Alzheimer's

and Parkinson's Diseases?

A Narrative Review.

Front. Physiol. 10:1556.

doi: 10.3389/fphys.2019.01556
Neurodegenerative diseases involve the progressive deterioration of structures within the central nervous system responsible for motor control, cognition, and autonomic function. Alzheimer's disease and Parkinson's disease are among the most common neurodegenerative disease and have an increasing prevalence over the age of 50 . Central in the pathophysiology of these neurodegenerative diseases is the loss of protein homeostasis, resulting in misfolding and aggregation of damaged proteins. An element of the protein homeostasis network that prevents the dysregulation associated with neurodegeneration is the role of molecular chaperones. Heat shock proteins (HSPs) are chaperones that regulate the aggregation and disaggregation of proteins in intracellular and extracellular spaces, and evidence supports their protective effect against protein aggregation common to neurodegenerative diseases. Consequently, upregulation of HSPs, such as HSP70, may be a target for therapeutic intervention for protection against neurodegeneration. A novel therapeutic intervention to increase the expression of HSP may be found in heat therapy and/or heat acclimation. In healthy populations, these interventions have been shown to increase HSP expression. Elevated HSP may have central therapeutic effects, preventing or reducing the toxicity of protein aggregation, and/or peripherally by enhancing neuromuscular function. Broader physiological responses to heat therapy have also been identified and include improvements in muscle function, cerebral blood flow, and markers of metabolic health. These outcomes may also have a significant benefit for people with neurodegenerative disease. While there is limited research into body warming in patient populations, regular passive heating (sauna bathing) has been associated with a reduced risk of developing neurodegenerative disease. Therefore, the emerging evidence is compelling and warrants further investigation of the potential benefits of heat acclimation and passive heat therapy for sufferers of neurodegenerative diseases.

Keywords: neurodegenerative disease, heat shock protein, passive heating, thermal therapy, body warming, alpha-synuclein 


\section{INTRODUCTION}

Humans are homeothermic and as such regulate their core body temperature within a narrow range. Perturbations to this homeostasis, induced by external environmental thermal stress or internally generated metabolic heat, produces both autonomic and behavioral responses designed to elicit a return of core body temperature toward thermal balance (Schlader and Vargas, 2019). While in an acute sense this stress response is a defense mechanism, regularly challenging the thermal equilibrium via active or passive thermal stress results in positive physiological and perceptual adaptations (Tyler et al., 2016). Recent research has shown positive therapeutic effects of passive heating for people with peripheral arterial disease (Neff et al., 2016; Akerman et al., 2019), chronic heart failure (Kihara et al., 2002; Ohori et al., 2012), diabetes (Hooper, 1999), and depression (Janssen et al., 2016). Passive heating also improves a range of health markers, including cardiovascular health indices, such as vascular function, blood pressure, and arterial stiffness (Brunt et al., 2016a,b), as well as metabolic health and glycemic control (Janssen et al., 2016; Kimball et al., 2018; Ely et al., 2019; Maley et al., 2019). Several mechanistic pathways may underpin these adaptations, including improved cellular respiration (Hafen et al., 2018), circulating factors (Brunt et al., 2019), and vascular shear stress (Tinken et al., 2009; Thomas et al., 2016). The upregulation of heat shock proteins (HSPs) as a result of acute and/or chronic (repeated) exposure to passive heating is also an adaptive outcome, which may provide a specific mechanistic pathway for improving health and function within the body (Faulkner et al., 2017; Brunt et al., 2018).

Recent reviews have identified the upregulation of HSPs as therapeutic targets for the treatment of neurodegenerative diseases including Parkinson's disease and Alzheimer's disease (Carman et al., 2013; Kalmar et al., 2014; Schapira et al., 2014; Ciechanover and Kwon, 2017; Webster et al., 2017; Klaips et al., 2018). Neurodegenerative diseases are characterized by the progressive deterioration of structures within the central nervous system responsible for motor control, cognition, and autonomic function. Alzheimer's and Parkinson's diseases are among the most common neurodegenerative diseases and have an increasing prevalence over the age of 50 (Pringsheim et al., 2014). Loss of protein homeostasis, due to protein mis-folding and aggregation of damaged proteins, is a hallmark of both Alzheimer's and Parkinson's diseases (Labbadia and Morimoto, 2015). HSPs function as chaperones to ensure appropriate cell function with distinct roles in the unfolded protein response, recognizing misfolded or mis-localized proteins that may be subsequently degraded by the proteasome, and are a key component of chaperone-mediated autophagy (Adachi et al., 2009; Stetler et al., 2010; Leak, 2014; Zarouchlioti et al., 2018). For their role in regulating protein homeostasis, HSP expression has been proposed as a therapeutic target for the treatment of these neurodegenerative diseases (Carman et al., 2013; Kalmar et al., 2014; Schapira et al., 2014; Ciechanover and Kwon, 2017; Webster et al., 2017; Klaips et al., 2018).

As physical and cognitive ability decline in Alzheimer's and Parkinson's diseases, passive heat therapy may yield an achievable alternative to the presently recommended exercise interventions in this population. Intriguingly, the incidence of Alzheimer's disease has recently been shown to be reduced in people who undertook moderate to frequent sauna bathing (Laukkanen et al., 2017). While the current evidence for heat therapy in neurodegenerative disease is associative and the mechanisms by which improved health outcomes are achieved have yet to be elucidated, the potential of passive heating in this population remains an alluring therapeutic option.

This review will examine pathophysiological determinants of common neurodegenerative disease, examine the evidence of an elevated HSP expression as a potential therapeutic intervention in common neurodegenerative diseases, and describe the role heat acclimation and passive heat therapy have in inducing HSP expression. In addition, central and peripheral adaptations to body warming in healthy adults, including improved muscular function, cerebral blood flow, and metabolic health, will be considered with their potential influence on neurodegenerative disease outcomes. Finally, considerations for undertaking heat acclimation and/or passive heating interventions in people with neurodegenerative diseases will be addressed.

\section{NEURODEGENERATIVE DISEASES}

\section{Epidemiology and Pathophysiology}

Central in the pathophysiology of neurodegenerative diseases is the loss of protein homeostasis and the progressive loss of selective neurons. Protein homeostasis involves a complex system of protein synthesis, folding, disaggregation, and degradation that ensures the correct function of the human body and particularly the central nervous system (Klaips et al., 2018). Loss of protein homeostasis, due to protein misfolding and aggregation of damaged proteins, is a hallmark of neurodegenerative diseases such as Alzheimer's and Parkinson's diseases (Labbadia and Morimoto, 2015). Alzheimer's and Parkinson's are the two most common degenerative neurological conditions and are more prevalent with advancing age. Both of these neurodegenerative diseases are progressive with pathological features demonstrating topographic distribution. The progressive loss of selective neurons includes amyloidosis, tauopathies, alpha-synucleinopathies, and proteinopathies, all of which have their own characteristic histopathological imaging features, as well as clinical symptomology. The diseases are incurable and result in long-term cognitive, psychological, motor, and non-motor impairments that have a profound impact on functional mobility, psychological well-being, independent living, and quality of life.

\section{Alzheimer's Disease}

Alzheimer's disease is the most prevalent neurodegenerative disease and is the most common form of dementia (Thies and Bleiler, 2012), which affects 40-50 million people worldwide (Prince et al., 2013; Nichols et al., 2019). Early stages of Alzheimer's presents with mild cognitive impairment involving memory loss and progresses with deficits in attention, language, and visuospatial abilities (Galton et al., 2000; 
Wattmo et al., 2016). Social withdrawal accompanies disease progression, as symptoms include a reduced capacity to perform activates of daily living, impaired executive function and judgment, along with disorientation (Wattmo et al., 2016). These outcomes have a significant impact on independence, quality of life, and years of life with a disability (Martyr et al., 2019). Furthermore, the economic cost of dementia is $\$ 968$ billion globally (Xu et al., 2017). These costs are born by individuals and their caregivers, social health services, as well as public and private health care providers (Castro et al., 2010). Due to the aging population, the prevalence and impact of Alzheimer's disease are anticipated to increase in the future (Prince et al., 2013; Nichols et al., 2019).

Neurodegenerative diseases such as Alzheimer's are marked by a loss of cellular protein homeostasis (Ciechanover and Kwon, 2017; Klaips et al., 2018). The pathophysiology of Alzheimer's is evidenced by intracellular and extracellular amyloid- $\beta$ plaques as well as neurofibrillary tangles of hyperphosphorylated tau (Montine et al., 2012; Ciechanover and Kwon, 2017). Neurodegeneration occurs as a result of the accumulation of tau proteins and atrophy of cerebral cortices. Amyloid deposits occur in the neocortex and hippocampus (Phases 1 and 2), the striatum (Phase 3), the brainstem (Phase 4), and the cerebellum (Phase 5) (Montine et al., 2012). In concert with abnormal protein accumulation, the pathogenesis of Alzheimer's disease may also involve vascular impairments leading to chronic cerebral hypoperfusion (de la Torre, 2004; Akinyemi et al., 2013; Sweeney et al., 2018). To combat these pathophysiological progressions, therapeutic interventions to improve protein quality control and regulation or improve vascular health and function have been recommended (Akinyemi et al., 2013; Ciechanover and Kwon, 2017).

\section{Parkinson's Disease}

Parkinson's disease is the second most common neurodegenerative disease, after Alzheimer's disease. For Parkinson's disease, the progressive degeneration of dopaminergic neurons in the substantia nigra pars compacta results in severe motor (e.g., tremor, rigidity, bradykinesia, postural instability) and non-motor symptoms (e.g., sleep disturbances, apathy, cognitive dysfunction, anxiety, depression) (Politis et al., 2010; Asahina et al., 2013). Both motor and non-motor impairments contribute to reduced physical activity and consequently decreased fitness in people with Parkinson's disease (Speelman et al., 2011). This decreased fitness exacerbates both pre-existing and disease-specific conditions including cardiovascular disease, muscle weakness, postural instability, osteoporosis, sleep disruption, impaired cognitive function, depression and constipation (Speelman et al., 2011). Estimates suggest that Parkinson's disease affects between 5 and 7 million people worldwide (Dorsey et al., 2018). The annual economic cost of Parkinson’s disease is estimated to be $£ 3.3$ billion in the United Kingdom (Findley, 2007), \$23 billion in the United States (Findley, 2007), \$6.3 billion in Australia (Access Economics (Firm) and Parkinson's Australia, 2007).

The degradation in neural function in Parkinson's disease is evidenced by degeneration of substantia nigral neurons, accumulation of alpha-synuclein and Lewy bodies, cortical atrophy and alteration in neural oscillatory activity between basal ganglia, thalamus, cortex, and brainstem areas. It has been proposed by Braak et al. (2003) that in Parkinson's disease, the topographic progress of neurodegeneration, follows patterns of alpha-synuclein aggregation expressed in Lewy neurites and Lewy bodies. This occurs first in the medulla and olfactory bulb, then progressively dorsally through the brainstem, mediobasal forebrain, limbic structures, higher-order sensory association and prefrontal areas, and finally to primary sensory and motor areas (Braak et al., 2003). A central tenet of this proposal is that the initial disease onset is a result of inflammatory processes in the enteric system that result in progression to the central nervous system via the vagal nerve (Breen et al., 2019). Additionally, deterioration in the vasculature of the brain resulting in abnormal cerebral perfusion patterns has been identified in people with Parkinson's disease, suggesting a role of cerebral blood flow in the pathophysiology of the disease (Melzer et al., 2011; Syrimi et al., 2017; Sweeney et al., 2018).

\section{Heat Shock Proteins as a Therapeutic Target}

Recent reviews have clearly identified the upregulation of HSPs as thermally activated therapeutic targets for the treatment of neurodegenerative diseases including Parkinson's and Alzheimer's (Carman et al., 2013; Kalmar et al., 2014; Schapira et al., 2014; Ciechanover and Kwon, 2017; Webster et al., 2017; Klaips et al., 2018). HSPs are a collective family of proteins, suffixed by their molecular weight (in kilodaltons; $\mathrm{kDa}$ ), which are present in both constitutively expressed, and inducible isoforms across several intracellular tissue sites and in extracellular fluid following stress (Kampinga et al., 2009). Relative to increased intracellular HSP content (a necessary component for protective cellular adaptation), the presence of extracellular changes in HSP concentration reflects a less pertinent (in the context of adaptation) transient stress response which acts as an acute signaling response. The $70 \mathrm{kDa}$ (HSPA) and $90 \mathrm{kDa}$ (HSPC) family of HSPs, hereafter referred to as HSP70 and HSP90, are generally the most widely studied responders to thermal stressors and are likely of most relevance within the field of heat therapy and heat adaptation for neurodegenerative disease (Luo et al., 2010; Fontaine et al., 2016; Lackie et al., 2017). HSP70 and HSP90 function as chaperones to ensure appropriate cell function and have distinct roles in the unfolded protein response, e.g., recognizing misfolded or mis-localized proteins that may be subsequently degraded by the proteasome, and are a key component of chaperone-mediated autophagy (Adachi et al., 2009; Stetler et al., 2010; Leak, 2014; Kampinga and Bergink, 2016; Zarouchlioti et al., 2018). It is outside of the focus of this review to describe each of these roles, with the reader directed elsewhere to contextualize these actions (Adachi et al., 2009; Stetler et al., 2010; Leak, 2014; Kampinga and Bergink, 2016; Zarouchlioti et al., 2018).

As therapeutic targets, HSP70 and HSP90 may be considered to have a direct and indirect role in neurodegenerative diseases. Direct roles for HSPs on the nervous system arise 
from the aforementioned notion that aggregation of misfolded proteins is characteristic of neurodegenerative diseases, including Parkinson's, Alzheimer's, and Huntington's (Stetler et al., 2010). In Parkinson's, HSP70 is reported as being of decreased gene expression (Mandel et al., 2005), while during proteomic profiling, reduced phosphorylation of HSP90 is also reported (Kulathingal et al., 2009). Pharmacological and animal models utilizing HSP expression (elevated HSP70 and reduced HSP90) have reduced the aggregation and toxicity of alpha-synuclein in Parkinson's disease (Auluck et al., 2002; Klucken et al., 2004; Danzer et al., 2011; Gao et al., 2015). In Alzheimer's, HSP70 may suppress the proteolysis of amyloid precursor protein (Hoshino et al., 2007) and in addition to HSP70, HSP90, and small HSPs reduce the formation of A-beta fibrils (Kudva et al., 1997; Lee et al., 2005; Wilhelmus et al., 2006a) and A-beta toxicity (Wilhelmus et al., 2006b) which subsequently form amyloid plaques. Tauopathy occurrence in Alzheimer's may also be positively impacted by HSP changes with HSP70 (Jinwal et al., 2009) and HSP90 (Evans et al., 2006; Luo et al., 2007). Further, HSPs have been found to regulate huntingtin via reduced cell aggregation in Huntington's disease (Muchowski et al., 2000; Sittler et al., 2001), and slows the muscle denervation of amyotrophic lateral sclerosis (Motor Neuron Disease) (Kieran et al., 2004; Kalmar et al., 2008, 2012).

Much of the literature describing these responses involve complex and isolated tissue/cell models to understand how HSP manipulation impacts upon neurodegenerative disease factors, thus direct application for humans remains unknown. However, with mechanistic support for the role of HSP augmentation to improve disease states, the application of heat therapy and/or heat adaptation in this context warrants further investigation.

\section{RESPONSES TO ACTIVE (EXERCISE HEAT ACCLIMATION) AND PASSIVE HEAT THERAPY IN HEALTHY ADULTS}

Physical activity and exercise have long been identified as mechanisms of inducing physiological stressors and subsequent positive adaptations in healthy (Tyler et al., 2016) and chronic disease (Hoffmann et al., 2016) populations. Unfortunately, those with increasing disease severity or diseases that challenge their motor control capabilities may be physically incapable of performing such beneficial exercise. Heat therapy has recently been targeted as a potential vehicle to evoke these positive thermal-induced adaptations in those precluded from undertaking exercise. Experimental investigations, large cohort surveys and reviews have expressed the potential for passive heating to improve physical and mental health in patients with cardiovascular disease (Brunt et al., 2016a,b; Maeda et al., 2018), diabetes (Kimball et al., 2018; Maley et al., 2019), peripheral arterial disease (Akerman et al., 2019), and depression (Janssen et al., 2016).

While there is a myriad of beneficial physiological and molecular effects of active and passive heating, this review will primarily focus specifically on the outcome of HSP expression, for its potential to influence proteostasis in neurodegenerative disease. For active and passive heating to be effective in increasing HSP expression, the minimum exposure requirements to elicit a desirable response in HSPs, from both acute and chronic (repeated) exposure, needs to be identified.

\section{Acute Effects of Body Warming on Heat Shock Proteins}

Transcription of HSP mRNA, an essential step before protein translation, is primarily regulated by Heat shock factor protein 1 (HSF-1) as part of the Heat Shock Response (Kregel, 2002). HSF-1 activation involves a complex series of regulatory events, including nuclear localization, oligomerization and acquisition of HSE-DNA binding, ultimately resulting in the transcription of HSP mRNA (Sarge et al., 1993) in response to the thermal and physiological challenge (McClung et al., 2008; Maloyan et al., 2011). Sufficient mRNA transcription then leads to increased protein within the stressed cell.

Precise parameters for intracellular increases, and thus cellular adaptation, have been less clearly defined. For example, mean core body temperature may not be the sole marker of an increase, rather the rate of change in core body temperature may be of greater importance to signal HSF-1 to HSP70 pathways. In the more common exercise-heat stress model, a recent analysis concluded that when transcription of the related HSP70 and HSP90 $\alpha$ mRNA is important, protocols should rapidly induce large, prolonged changes in core body temperature (Gibson et al., 2016). This notion was supported by evidence that, when analyzed collectively, significant predictors of the postexercise change in HSP70 and HSP90 $\alpha$ mRNA were the change in mean and peak core body temperature, and the duration core body temperature was $\geq 38.5^{\circ} \mathrm{C}$ (Gibson et al., 2016). It should be acknowledged that these data describe responses to exercise-heat stress, an intervention that is likely to be challenging to implement in clinical populations. Accordingly, passive heating via body warming may prove to be a more efficacious intervention.

The HSP response to localized or whole body warming has also been investigated. In passive heating models, increases in HSP70 and HSP90 mRNA have been evidenced as peaking $30 \mathrm{~min}$ following $90 \mathrm{~min}$ of local heating to either the thigh or the whole leg of healthy human volunteers (Kuhlenhoelter et al., 2016). Regrettably, no intramuscular temperature data is available from this experiment to assist with identifying minimum exposure requirement. This increase following resting, local heat stress which does not alter core body temperature offers mechanistic insight as elevations in blood flow and shear stress provide a non-core body temperature dependent HSP response that parallels transcription of angiogenic markers (Kuhlenhoelter et al., 2016). Not all experimental work has observed changes in HSP following passive heating. Leg immersion in hot water at $45^{\circ} \mathrm{C}$ for $60 \mathrm{~min}$, eliciting an increased intramuscular temperature of $>39^{\circ} \mathrm{C}$, did not affect muscle HSPs (HSP70, HSC70, HSP60, HSP27, alphaB-crystallin) in healthy young humans (Morton et al., 2007). It should be noted that this null-observation came $48 \mathrm{~h}$ following, rather than immediately after heating, which may provide a rationale 
for the response. These data share commonality with responses observed elsewhere in relation to HSP70 and HSP27 stasis $24 \mathrm{~h}$ following $\sim 80 \mathrm{~min}$ of heating at $\sim 49^{\circ} \mathrm{C}$ (Vardiman et al., 2013) to increase intramuscular temperature also to $>39^{\circ} \mathrm{C}$, suggesting that the dose of heat therapy may be an important driver of HSP response or that the inconsistent timing of differential tissue sampling are experimental artifacts impacting current understanding.

Examination of extracellular changes in HSP70 during acute exercise-heat stress in humans has identified that the endogenous requirement for extracellular HSP70 release (at the cessation of exercise) may be a core body temperature mean of $>38.5^{\circ} \mathrm{C}$ (peak of $39.2^{\circ} \mathrm{C}$ ) for $56 \mathrm{~min}$, alongside moderate exercising intensities (Gibson et al., 2014). Although changes may occur more rapidly (within $27 \mathrm{~min}$ ) if exercise intensities are higher (Périard et al., 2012). Both the change in and final core body temperature attained are relevant to extracellular HSP70 release (Périard et al., 2012) and indicate achieving substantial elevations in thermal parameters is important when administering exercise-heat exposures to increase thermotolerance in whole-body models.

\section{Chronic Effects of Body Warming on Heat Shock Proteins}

The HSP responses to exercise-heat acclimation have been reviewed previously, with an acknowledgment that the intervention is an effective means to augment cellular thermotolerance, which may subsequently protect vital organs from deleterious effects of heat stress in humans (Amorim et al., 2015). An internal temperature threshold for intracellular HSP70 induction may exist, though it is also possible that this response occurs once a certain variation of internal, wholebody temperature is reached alongside additional stressors (Magalhães et al., 2010). For example, during a 10-day heat acclimation period, Magalhães et al. (2010) demonstrated the largest changes in post-exercise intracellular HSP70 when a core body temperature $>39.0^{\circ} \mathrm{C}$ was achieved. In contrast, Yamada et al. (2007) and Hom et al. (2012) reported no change in HSP70 in response to a lower core body temperature (mean maximum of $\sim 38.5^{\circ} \mathrm{C}$ ) following 10 days of heat acclimation. HSP70 and HSP90 mRNA transcription occur at a series of core body temperature thresholds during $90 \mathrm{~min}$ of exercise-heat stress (mean $37.6-38.2^{\circ} \mathrm{C}$; peak $38.1-39.1^{\circ} \mathrm{C}$ ) (Gibson et al., 2015a,b) therefore the dose of heat stress to elicit translation may be greater than that required to elicit transcription.

In human whole-body passive heating models, such as hot water immersion of $>60$ min whereby core body temperature is increased, higher extracellular HSP70 concentration (Faulkner et al., 2017), and intracellular HSP70 changes (Oehler et al., 2001), have been reported. The beneficial response once again is not unanimous, with others reporting chronic change (following 2 weeks of repeated therapy) in intracellular HSP70 after 4560 min of passive heat therapy (Hoekstra et al., 2018). In a similar manner to that described for local heating, the dose of stress may be important given the lack of change in studies using $60 \mathrm{~min}$ heating (Hoekstra et al., 2018), in comparison to those who do report an acute increase in intracellular HSP70 following $120 \mathrm{~min}$ heating in $39^{\circ} \mathrm{C}$ water (Oehler et al., 2001).

Intracellular HSP70 and HSP90 levels in peripheral blood mononuclear cells (PBMC) are increased after 6-10 days of long term exercise-heat acclimation (Yamada et al., 2007; McClung et al., 2008). The two larger HSPs appear to be related with regards to exercise-heat stress changes, as an HSP70 increase of $\sim 21 \%$ was correlated with HSP90 increases of $\sim 18 \%$ (McClung et al., 2008). In vitro analysis of PBMC obtained from 10-day exercise-heat acclimated individuals exhibit greater blunting of the HSP response to heat shock of $43^{\circ} \mathrm{C}$ for $60 \mathrm{~min}$ (compared to unacclimated). This blunted pre-post response is indicative of increased thermotolerance and/or cellular protection from stress, likely due to increased basal intracellular HSP content and appears directly related to the degree of physiological heat acclimation (lower core temperature), thus the adapted individual/cell experiences lesser relative stress at the same absolute temperature (McClung et al., 2008).

The notion of individual differences in the responses to local heat therapy has been highlighted in a study observing that $24 \mathrm{~h}$ following $40 \mathrm{~min}$ of heat treatment (diathermy followed by heat packs), female subjects significantly increased HSP70 (+58\%) and phosphorylation of HSP27 (+100\%) content compared to the untreated leg (Touchberry et al., 2007). In comparison, male subjects had non-significant increases in HSP70 (+35\%) and HSP27 phosphorylation $(+32 \%)$ within skeletal muscle (Touchberry et al., 2007). These sex-specific responses are intriguing and warrant future investigation given no differences in Hsp70 mRNA have been reported during isothermic heat acclimation (Mee et al., 2016) and were not reported in the mixedsex cohort undertaking passive heating described above (Kuhlenhoelter et al., 2016).

\section{Central and Peripheral Effects of Body Warming}

The administration of heat therapy and heat acclimation may provide additional benefits in the context of neurodegenerative diseases in relation to skeletal muscle function, cerebral blood flow, and metabolic health. Adverse reductions in strength and lean body mass are symptoms of neurodegenerative diseases, including Alzheimer's disease (Burns et al., 2010; Buchman and Bennett, 2011), Parkinson's disease (Berardelli et al., 2001; Petroni et al., 2003; Cano-de-la-Cuerda et al., 2010) and Amyotrophic Lateral Sclerosis (Gubbay et al., 1985; Munsat et al., 1988; Kiernan et al., 2011). While various mechanisms are at play, muscle atrophy and decreased strength likely owe to symptominfluenced reductions in physical activity, along with central and peripheral nervous system changes that limit muscle activation (Hass et al., 2007). Furthermore, reduced cerebral blood flow and poor metabolic health profiles may also be related to disease progression (de la Torre, 2004; Akinyemi et al., 2013; Bharadwaj et al., 2017; Sweeney et al., 2018). As there is a potential benefit to be gained, the below reviews the current 
developing understanding of the acute and chronic effects of elevated temperature on skeletal muscle function, cerebral blood flow, and markers of metabolic health.

\section{Skeletal Muscle Function}

Increases in skeletal muscle temperature have long been accepted to improve acute muscle force, power and contractility (Bergh and Ekblom, 1979; Davies and Young, 1983; Bennett, 1984). Contrastingly, the inverse relationship between high core body temperature and muscle torque, muscle recruitment patterns, and voluntary activation is also documented (Morrison et al., 2004; Todd et al., 2005; Thomas et al., 2006). Importantly, however, these outcomes are most often viewed with a shortterm lens, with limited understanding of the effects of time or repeated heat exposures on skeletal muscle in humans (Brazaitis and Skurvydas, 2010; Goto et al., 2011; Racinais et al., 2017).

Passive heating has been reported in experimental designs examining effects on exercise-induced muscle damage (Nosaka et al., 2007; Touchberry et al., 2012), recovery from muscle injury (Kojima et al., 2007; Oishi et al., 2009; Takeuchi et al., 2014) and immobilization (Selsby and Dodd, 2005; Senf et al., 2008; Dodd et al., 2009), and muscle hypertrophy (Uehara et al., 2004; Ohno et al., 2010) in animal models. The rationale for passive heat application relates to the altered cascade of inflammation and HSP expression that interact with mitochondrial biogenesis and muscle growth (Yoshihara et al., 2013; McGorm et al., 2018). Increases in wet muscle mass and protein content in rat soleus muscle have been described 7 days after a $60 \mathrm{~min}$ exposure to a $41-42^{\circ} \mathrm{C}$ heat chamber (Uehara et al., 2004; Ohno et al., 2010). Further, Kodesh and Horowitz (2010) observed higher muscle mass/body weight ratios in rats following 30 days of acclimation to $34^{\circ} \mathrm{C}$ environmental heat compared to a $24^{\circ} \mathrm{C}$ control. Similarly, in healthy men, Goto et al. (2011) saw an increased cross-sectional area of fibers in the vastus lateralis (8.3\%) using a steam-generating sheet applied to the quadriceps muscle for $8 \mathrm{~h} \cdot \mathrm{day}^{-1}$ and 4 days.week ${ }^{-1}$ across a 10-week intervention. Collectively, it might be concluded that passive heating could support cell proliferation and facilitate muscle hypertrophy (Naito et al., 2000; Goto et al., 2004; Uehara et al., 2004). Such outcomes would be particularly beneficial to those experiencing neurodegenerative disease, particularly as passive heating appears also to attenuate human skeletal muscle atrophy (Hafen et al., 2019).

Most pertinent from a translational perspective, improved strength has been demonstrated to couple the increased skeletal muscle growth after passive heating (Goto et al., 2011; Racinais et al., 2017). Higher isometric knee extensor torque (5.8\%) was achieved after 10 weeks of heat stress, which the authors explained as potentially relating to the increase of myonuclear number (Goto et al., 2011). Goto et al. (2011) also found a $4 \%$ increase in knee extensor strength in the non-heated leg. While the contralateral effects of unilateral resistance training are acknowledged (Lee and Carroll, 2007; Frazer et al., 2018), this phenomenon may imply that there are central nervous system effects of chronic passive heating. A potential role of circulating factors has also been proposed (Hendy and Lamon, 2017). The site(s) of possible neural adaptation explaining cross-education remain unclear. However, it is conceivable that adaptations could occur at the spinal and/or cortical level considering the noted decline in descending motor drive during acute episodes of hyperthermia (Todd et al., 2005; Périard et al., 2012; Ross et al., 2012). It seems that higher body temperature acutely impairs somatosensory processing (Nakata et al., 2015), though how adaptation to passive heating might affect neural activity in healthy or diseased states in thermoneutral conditions remains to be elucidated. Regardless, adaptation to passive heat therapy is promising, particularly in a rehabilitation setting and for those with neurodegenerative diseases, as acute stress may increase motor cortex excitability and augment motor skill acquisition (Littmann and Shields, 2016).

\section{Cerebral Blood Flow}

Another avenue by which passive heating may have a therapeutic effect is through improved cerebral blood flow. Reduced cerebral blood flow and dysfunction in the blood-brain barrier have been identified in neurodegenerative diseases, including Alzheimer's and Parkinson's (de la Torre, 2004; Akinyemi et al., 2013; Sweeney et al., 2018). Both motor and cognitive impairments have been associated with poor perfusion in several brain regions in Parkinson's disease (Melzer et al., 2011). Similarly, overall and regional cerebral blood flow reductions have been associated with cognitive decline in mild cognitive impairment and Alzheimer's disease (Leeuwis et al., 2017). For these reasons, the vasculature supplying blood to and across the brain are also relevant targets to examine the beneficial adaptations of passive heat therapy for neurodegenerative diseases.

Several vascular adaptations attributable to heat therapy have been reported. These have included improved flow-mediated dilation (Brunt et al., 2016a), increased pulse wave velocity (an index of arterial stiffness) (Brunt et al., 2016a), reduced carotid intima thickness (Brunt et al., 2016a) improved capillarization (Hesketh et al., 2019) and subsequently enhanced systemic blood pressure profiles (Brunt et al., 2016a; Akerman et al., 2019). Mechanistically, HSP27 has been shown to reduce intimal hyperplasia (Connolly et al., 2003), with greater carotid intima thickness associated with reduced cerebral blood flow (Sojkova et al., 2010). Undesirable vascular hypertrophy can also be mitigated against via HSP70 associated inhibition of Angiotension II (Zheng et al., 2006), with HSP90 conferring a more general adaptation aligned to the stabilization of the vascular endothelial growth factor (VEGF) upstream target hypoxia-inducible factor-1 (HIF-1 $\alpha$ ) (Maloyan et al., 2005), and elevated endothelial nitric oxide production and improved the stabilization and bioavailability of endothelial nitric oxide synthase (Averna et al., 2008). Collectively these vascular adaptations observed in passive heating interventions have the potential to maintain cerebral blood flow and blood-brain barrier function, outcomes which may have beneficial effects for cognitive function in Alzheimer's and Parkinson's diseases.

\section{Metabolic Health}

Markers of metabolic health may also play a role in the pathogenesis of neurodegeneration in Alzheimer's disease. The neurodegeneration seen in Alzheimer's disease has been linked 


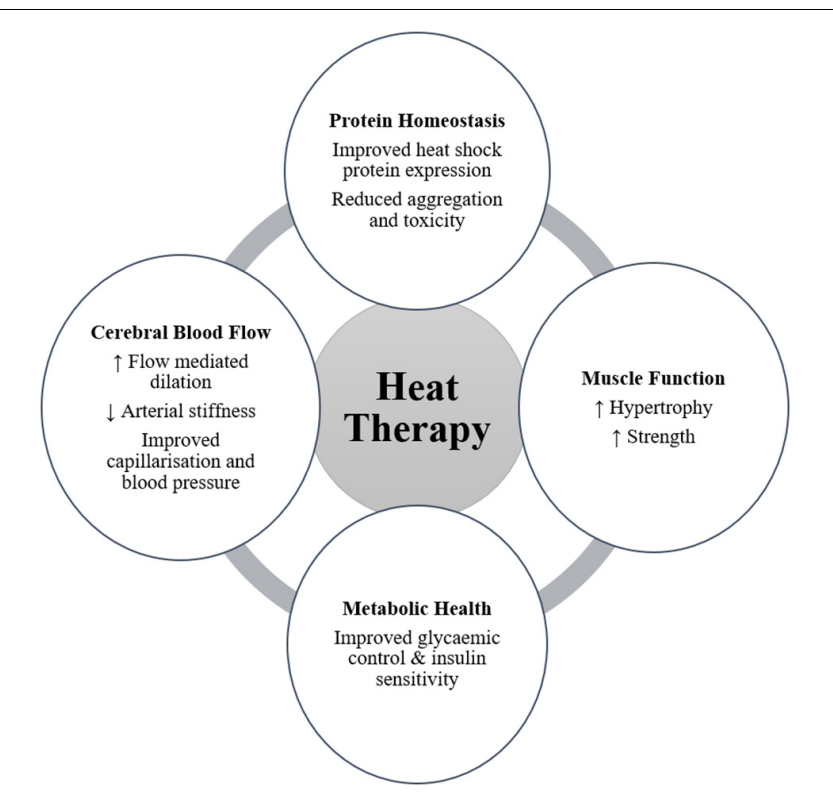

FIGURE 1 | Potential benefits arising from heat therapy for people with neurodegenerative disease ( $\uparrow$ symbolizes an increasing effect; $\downarrow$ symbolizes a decreasing effect). with impaired cerebral insulin signaling and glucose metabolism (Bharadwaj et al., 2017). The loss of protein homeostasis (A $\beta$ accumulation and tau hyperphosphorylation), synaptic degeneration, and neural dysfunction have been associated with these impairments to normal metabolic processes (Bharadwaj et al., 2017). Recent research has therefore proposed therapeutic interventions to improve insulin signaling and reduce insulin resistance. Interestingly, heat therapy has been proposed for people with type II diabetes, and early studies have highlighted a reduction in fasting plasma glucose following repeated hot water bath immersions over 3 weeks (Hooper, 1999). Furthermore, chronic heat therapy interventions have improved glucose tolerance and insulin sensitivity in women with polycystic ovary syndrome who experience obesity and metabolic dysfunction (Ely et al., 2019). Therefore, the effects of heat therapy on metabolic health are another potential avenue of therapeutic benefit for people with neurodegenerative disease.

\section{Summary}

For individuals who do not experience these important physiological stressors through habitual activity and exercise, heat therapy may provide a vehicle to achieve a range of health and physiological benefits (Figure 1). Much remains to be understood with regards to the mechanisms and stimuli required to elicit the desired increases in relevant HSPs following heat therapy, in addition to further quantifying the magnitude of importance of these responses. Additionally, the potential to improve muscular function, cerebral blood flow, and markers of metabolic health offer significant benefit for people with a neurodegenerative disease by improving their quality of life and reducing disease severity. Part of the present ambiguity results from the utilization of different methods, e.g., heating technique, heating duration and magnitude, tissue sample site and time points, across experimental studies. Despite the need for further clarity regarding the mechanistic underpinnings and best practice implementation, the opportunities to investigate a tolerable heat therapy model in a relevant target population exists and should be encouraged.

\section{BODY WARMING IN PEOPLE WITH NEURODEGENERATIVE DISEASES}

\section{Evidence for a Potential Benefit}

At present, the authors are not aware of any studies that have directly assessed the effects of active or passive body warming on HSP release, and disease severity or progression, in people with neurodegenerative diseases. Therefore, this review will draw on findings from epidemiological studies, and indirect studies of other interventions such as exercise, that have shown benefits among people with neurodegenerative diseases.

Habitual body warming, through sauna bathing or exercise, has been shown to reduce the risk of developing neurodegenerative diseases. Regular passive heating has been associated with a reduced risk of developing neurodegenerative diseases, including Alzheimer's (Heinonen and Laukkanen, 2018). Men participating in sauna bathing 2-3 or 4-7 times per week had a 0.80 and 0.35 hazard ratio for developing Alzheimer's disease compared to men who sauna once per week or less (Laukkanen et al., 2017). Regular exercise also has a protective effect on the risk of developing Alzheimer's and Parkinson's diseases (Paillard et al., 2015). Consistent and frequent participation in moderate to vigorous physical activity was found to reduce the risk of Parkinson's disease by up to $40 \%$ (Xu et al., 2010). Similarly, exercising three or more times per week is associated with a lower incidence rate of dementia and Alzheimer's (Larson et al., 2006). While these studies do not elucidate the potential mechanisms by which a protective effect is elicited, it does lend anecdotal evidence toward the expression of HSP through regular body warming as a distinct possibility.

Further to a preventative effect, exercise has been described as having a restorative effect on the neurodegeneration observed in Alzheimer's and Parkinson's diseases (Loprinzi et al., 2013; Paillard et al., 2015). Clinical and epidemiological studies have provided evidence supporting the conclusion that exercise has therapeutic value by reducing the symptoms and slowing disease progression (Ransmayr, 2011; Hou et al., 2017; Liu et al., 2019). Moderate to high-intensity aerobic exercises, such as treadmill walking or assisted cycling, are recommended for improved motor and cognitive function in Parkinson's disease (Ahlskog, 2011; Salgado et al., 2013; Evens and Clark, 2017). High-intensity treadmill exercise of $30 \mathrm{~min}$ at a target heart rate prevented Parkinson's disease progression, compared to moderate intensity and control (Schenkman et al., 2018). Furthermore, interval exercises (alternating periods of low and high intensity assisted cycling) have shown positive improvements in functional ability in Parkinson's patients (Uygur et al., 2015, 2017). Immersion 
in warm water $\left(33^{\circ} \mathrm{C}\right)$ for $50 \mathrm{~min}$ while performing dualtask exercises (combining physical movements with cognitive tasks) was found to improve functional mobility (timed up and go, and five-time sit-to-stand) among people with Parkinson's disease following 3 months of twice-weekly exposures (Silva and Israel, 2019).

Exercise interventions have also had significant effects on slowing the progression of Alzheimer's disease. Over 1 year, people with Alzheimer's disease who participated in twiceweekly 1 -h exercise sessions showed reduced rates of decline in measures of functional independence and physical performance, compared to control participants (Pitkala et al., 2013). In a similar intervention, the ability to perform activities of daily living declined significantly slower in people with Alzheimer's disease performing twice-weekly exercise programs (Rolland et al., 2007). A 6-month walking program has also shown people with Alzheimer's disease to be able to maintain cognitive function on the Mini Mental State Exam (MMSE), compared to significant declines in those not exercising (Venturelli et al., 2011). Overall, there is compelling evidence that exercise improves motor and cognitive function in neurodegenerative disease and it is therefore recommended by clinicians (Ransmayr, 2011; Hou et al., 2017; Liu et al., 2019). However, exercise and body warming interventions should consider the difficulties in performing such activities for these populations (section "Considerations for Heat Therapy for People With Neurodegenerative Disease").

The studies of moderate to high-intensity exercise among neurodegenerative disease populations provide circumstantial evidence that the assumed body warming experienced may be contributing to the beneficial effects observed. While there may be many avenues by which exercise and body warming promote improved health and function, the role of body temperature elevation, thermoregulatory responses, and HSP expression have been overlooked in these experiments. Given the growing body of evidence that supports the expression of HSPs as therapeutic targets for Alzheimer's and Parkinson's diseases (section "Heat Shock Proteins As a Therapeutic Target"), there is a clear need for future investigations of passive heating to monitor thermoregulation and HSP responses in people with these neurodegenerative diseases.

\section{Considerations for Heat Therapy for People With Neurodegenerative Disease}

An important consideration in conducting heat acclimation and heat therapy for older adults and clinical populations will be how their impairments or any co-morbidities may affect their ability to perform and tolerate these interventions. Firstly, their disease severity may impair their physical ability to perform movements effectively and safely (Kerr et al., 2010; Buchman and Bennett, 2011). Secondly, neurodegeneration may cause deficits in thermoregulatory processes. In Parkinson's disease, neural degeneration in higher-order brain centers including the hypothalamus is associated with impaired sudomotor function which in turn may influence their tolerance to body warming (LeDoux, 2013).

Neurodegenerative diseases such as Parkinson's and Motor Neuron Disease primarily affect motor control. As the diseases progress, motor function deteriorates resulting in impaired gait and balance and an increased risk of falls (Pickering et al., 2007). While Alzheimer's is usually associated with cognitive impairments, significant motor impairments are also associated with this disease (Buchman and Bennett, 2011). Therefore, exercise and heat acclimation interventions should consider the level of impairment of their target population and how the risk of falls and injury may be managed. As such, in these populations where movement is limited, passive heat therapy may be an achievable alternative to exercise interventions.

The autonomic nervous system, responsible for thermoregulation, can exhibit deficits in neurodegenerative diseases, specifically in the thermoeffector responses of sweating and skin blood flow. Abnormalities in the sweating response, hyperhidrosis and/or hypohidrosis, are commonly reported in Parkinson's disease (De Marinis et al., 1991; Swinn et al., 2003; Schestatsky et al., 2006) and may be more prominent with increasing age and disease severity of patients (Saito and Kogure, 1989). Hypohidrosis, an absence of the sweating or reduced sweat output, may reduce effective body cooling during exercise and body warming. However, the sweating response is highly individualized, and compromised sweating in one body region may be compensated by increased sweating in other body regions (Schestatsky et al., 2006). Careful attention should, therefore, be given to the rate of body warming people with Parkinson's disease may experience, and ensuring appropriate cooling strategies are available.

Cardiovascular regulation of blood pressure is also influenced by neurodegenerative disease. The expected elevation in heart rate and blood pressure may be blunted in people with Parkinson's disease, and they may also experience post-exercise hypotension (Asahina et al., 2013). Orthostatic intolerance is also reported in $10-60 \%$ of people with Parkinson's disease (Senard et al., 1997; Wüllner et al., 2007). These cardiovascular impairments may influence their ability to tolerate exercise and body warming and should be considered in determining individual suitability for heat therapy and heat acclimation. The modality of passive heating may therefore also be an important factor in determining appropriate therapeutic techniques. Infrared sauna bathing has been reported to promote lower cardiovascular strain than traditional sauna techniques (Mero et al., 2015) and may be one avenue that could be investigated for suitability in these at-risk populations.

\section{FUTURE DIRECTIONS}

Overall, there are three key points from the scientific literature that support a proposal for a therapeutic effect of heat therapy or heat acclimation to promote HSP expression in people with neurodegenerative disease. These include, (1) Exercise, sufficient to raise core body temperature, is currently recommended for people with neurodegenerative disease (e.g., Parkinson's and Alzheimer's diseases) as it has been shown to improve their symptoms; (2) Elevated HSP levels have been identified as a therapeutic target to reduce protein aggregation and toxicity; and (3) Exercise and body warming have been shown to elevate HSP 
expression in healthy adults. Furthermore, heat therapy may have additional benefits for muscle function, vasculature health and cerebral blood flow, and indicators of metabolic health, which have also been implicated in the pathophysiological presentation of neurodegenerative diseases. These findings from the current scientific literature support the proposal for further investigation into the potentially beneficial adaptations for people with neurodegenerative diseases to heat therapy and heat acclimation.

Initial research is required to establish the acute effects of heat therapy and/or heat acclimation in people with neurodegenerative diseases. As these diseases may involve impairment of autonomic pathways involved in thermoregulation, research is required to elucidate the thermoeffector responses, sweating and skin blood flow, to acute heat stress and how these may affect tolerance to body warming. Alongside these outcomes HSP expression, muscular adaptations, and vasculature function responses to body warming should be measured in neurodegenerative disease populations, to determine the presence of a similar response to body warming as seen in healthy adults, and the magnitude of the response in relation to the tolerable limits of body warming. Consequent to acute observations that tolerable heat exposures promote the desirable HSP response and vascular adaptations, further investigation should then pursue the effects of chronic or repeated heat therapy and/or heat acclimation on these responses and indicators of disease severity and progression. Finally, an understanding of the dose-response relationship between frequency and intensity of body warming and improved symptomology should be determined. In concert with these research efforts, investigations of the underlying mechanisms by which HSP expression and body warming may improve neuromuscular function are warranted.

\section{CONCLUSION}

While the current evidence for heat therapy in neurodegenerative disease is associative and the mechanisms of improved

\section{REFERENCES}

Access Economics (Firm), and Parkinson's Australia, (2007). Living with Parkinson's Disease : Challenges and Positive Steps for the Future. Scullin: Access Economics.

Adachi, H., Katsuno, M., Waza, M., Minamiyama, M., Tanaka, F., and Sobue, G. (2009). Heat shock proteins in neurodegenerative diseases: pathogenic roles and therapeutic implications. Int. J. Hyperthermia 25, 647-654. doi: 10.3109/ 02656730903315823

Ahlskog, J. E. (2011). Does vigorous exercise have a neuroprotective effect in Parkinson disease? Neurology 77, 288-294. doi: 10.1212/WNL. 0b013e318225ab66

Akerman, A. P., Thomas, K. N., van Rij, A. M., Body, E. D., Alfadhel, M., and Cotter, J. D. (2019). Heat therapy vs. supervised exercise therapy for peripheral arterial disease: a 12-week randomized, controlled trial. Am. J. Physiol. Heart Circ. Physiol. 316, H1495-H1506.

Akinyemi, R. O., Mukaetova-Ladinska, E. B., Attems, J., Ihara, M., and Kalaria, R. N. (2013). Vascular risk factors and neurodegeneration in ageing related health outcomes have yet to be elucidated, the potential of passive heating in this population remains an alluring therapeutic option. Heat acclimation and heat therapy have been shown to improve HSP responses in healthy adults, as well as induce additional benefits for skeletal muscle function and cerebral blood flow. Furthermore, HSPs have been identified as therapeutic targets to restore protein homeostasis and reduce protein toxicity in several neurodegenerative diseases. While circumstantial evidence exists that body warming may promote improved health and function in neurodegenerative disease, through exercise or sauna bathing, there is yet to be any direct studies of body warming, thermal tolerance, and HSP responses in these populations. For individuals who do not experience these important physiological stressors through habitual activity and exercise, heat therapy may provide a vehicle to achieve improved health and slowed disease progression in people with neurodegenerative disease, and, therefore, warrants further investigation.

\section{AUTHOR CONTRIBUTIONS}

All authors contributed to the planning and writing of the manuscript. Specifically, AH contributed to the design, writing, and review of the manuscript and was the primary contributor to section "Body Warming in People With Neurodegenerative Diseases." GM contributed to the design, writing, and review of the manuscript and was the primary contributor to section "Central and Peripheral Effects of Body Warming." OG contributed to the writing and review of the manuscript and primarily contributed to sections "Heat Shock Proteins As a Therapeutic Target," "Acute Effects of Body Warming on Heat Shock Proteins," and "Chronic Effects of Body Warming on Heat Shock Proteins." GK contributed to writing section "Epidemiology and Pathophysiology." IS contributed to the overall plan and design of the manuscript and writing sections "Introduction" and "Future Directions."

dementias: Alzheimer's disease and vascular dementia. Curr. Alzheimer Res. 10, 642-653.

Amorim, F. T., Fonseca, I. T., Machado-Moreira, C. A., and Magalhães, F. D. C. (2015). Insights into the role of heat shock proteins 72 to whole-body heat acclimation in humans. Temperature 2, 499-505. doi: 10.1080/23328940.2015. 1110655

Asahina, M., Vichayanrat, E., Low, D. A., Iodice, V., and Mathias, C. J. (2013). Autonomic dysfunction in parkinsonian disorders: assessment and pathophysiology. J. Neurol. Neurosurg. Psychiatr. 84:674.

Auluck, P. K., Chan, H. Y. E., Trojanowski, J. Q., Lee, V. M. Y., and Bonini, N. M. (2002). Chaperone suppression of alpha-synuclein toxicity in a Drosophila model for Parkinson's disease. Science 295, 865-868.

Averna, M., Stifanese, R., De Tullio, R., Passalacqua, M., Salamino, F., Pontremoli, S., et al. (2008). Functional role of HSP90 complexes with endothelial nitricoxide synthase (eNOS) and calpain on nitric oxide generation in endothelial cells. J. Biol. Chem. 283, 29069-29076. doi: 10.1074/jbc.M803638200

Bennett, A. F. (1984). Thermal dependence of muscle function. Am. J. Physiol. Regul. Integr. Comp. Physiol. 247, R217-R229. 
Berardelli, A., Rothwell, J. C., Thompson, P. D., and Hallett, M. (2001). Pathophysiology of bradykinesia in Parkinson's disease. Brain 124, 2131-2146.

Bergh, U., and Ekblom, B. (1979). Influence of muscle temperature on maximal muscle strength and power output in human skeletal muscles. Acta Physiol. Scand. 107, 33-37.

Bharadwaj, P., Wijesekara, N., Liyanapathirana, M., Newsholme, P., Ittner, L., Fraser, P., et al. (2017). The link between type 2 diabetes and neurodegeneration: roles for Amyloid-beta, Amylin, and Tau proteins. J. Alzheimer Dis. 59, 421432. doi: 10.3233/JAD-161192

Braak, H., Del Tredici, K., Rub, U., de Vos, R. A., Jansen Steur, E. N., and Braak, E. (2003). Staging of brain pathology related to sporadic Parkinson's disease. Neurobiol. Aging 24, 197-211.

Brazaitis, M., and Skurvydas, A. (2010). Heat acclimation does not reduce the impact of hyperthermia on central fatigue. Eur. J. Appl. Physiol. 109, 771-778. doi: 10.1007/s00421-010-1429-3

Breen, D. P., Halliday, G. M., and Lang, A. E. (2019). Gut-brain axis and the spread of alpha-synuclein pathology: vagal highway or dead end? Mov. Disord. 34, 307-316. doi: $10.1002 / \mathrm{mds} .27556$

Brunt, V. E., Eymann, T. M., Francisco, M. A., Howard, M. J., and Minson, C. T. (2016a). Passive heat therapy improves cutaneous microvascular function in sedentary humans via improved nitric oxide-dependent dilation. J. Appl. Physiol. 121, 716-723. doi: 10.1152/japplphysiol.00424.2016

Brunt, V. E., Howard, M. J., Francisco, M. A., Ely, B. R., and Minson, C. T. (2016b). Passive heat therapy improves endothelial function, arterial stiffness and blood pressure in sedentary humans. J. Physiol. 594, 5329-5342. doi: 10. 1113/JP272453

Brunt, V. E., Weidenfeld-Needham, K. M., Comrada, L. N., Francisco, M. A., Eymann, T. M., and Minson, C. T. (2019). Serum from young, sedentary adults who underwent passive heat therapy improves endothelial cell angiogenesis via improved nitric oxide bioavailability. Temperature 6, 169-178. doi: 10.1080/ 23328940.2019.1614851

Brunt, V. E., Wiedenfeld-Needham, K., Comrada, L. N., and Minson, C. T. (2018). Passive heat therapy protects against endothelial cell hypoxia-reoxygenation via effects of elevations in temperature and circulating factors. J. Physiol. 596, 4831-4845. doi: 10.1113/JP276559

Buchman, A. S., and Bennett, D. A. (2011). Loss of motor function in preclinical Alzheimer's disease. Expert Rev. Neurother. 11, 665-676. doi: 10.1586/ern.11.57

Burns, J. M., Johnson, D. K., Watts, A., Swerdlow, R. H., and Brooks, W. M. (2010). Reduced lean mass in early Alzheimer disease and its association with brain atrophy. Arch. Neurol. 67, 428-433. doi: 10.1001/archneurol.2010.38

Cano-de-la-Cuerda, R., Perez-de-Heredia, M., Miangolarra-Page, J. C., MunozHellin, E., and Fernandez-de-Las-Penas, C. (2010). Is there muscular weakness in Parkinson's disease? Am. J. Phys. Med. Rehabil. 89, 70-76. doi: 10.1097/PHM. 0b013e3181a9ed9b

Carman, A., Kishinevsky, S., Koren, J. III, Lou, W., and Chiosis, G. (2013). Chaperone-dependent Neurodegeneration: a molecular perspective on therapeutic intervention. J. Alzheimer Dis. Parkinsonism 2013(Suppl. 10):007.

Castro, D. M., Dillon, C., Machnicki, G., and Allegri, R. F. (2010). The economic cost of Alzheimer's disease: family or public health burden? Dement. Neuropsychol. 4, 262-267. doi: 10.1590/S1980-57642010DN40400003

Ciechanover, A., and Kwon, Y. T. (2017). Protein quality control by molecular chaperones in Neurodegeneration. Front. Neurosci. 11:185. doi: 10.3389/fnins. 2017.00185

Connolly, E. M., Kelly, C. J., Chen, G., O’Grady, T., Kay, E., Leahy, A., et al. (2003). Pharmacological induction of HSP27 attenuates intimal hyperplasia in vivo. Eur. J. Vasc. Endovasc. Surg. 25, 40-47.

Danzer, K. M., Ruf, W. P., Putcha, P., Joyner, D., Hashimoto, T., Glabe, C., et al. (2011). Heat-shock protein 70 modulates toxic extracellular alpha-synuclein oligomers and rescues trans-synaptic toxicity. FASEB J. 25, 326-336. doi: 10. 1096/fj.10-164624

Davies, C. T., and Young, K. (1983). Effect of temperature on the contractile properties and muscle power of triceps surae in humans. J. Appl. Physiol. 55, 191-195.

de la Torre, J. C. (2004). Is Alzheimer's disease a neurodegenerative or a vascular disorder? Data, dogma, and dialectics. Lancet Neurol. 3, 184-190.

De Marinis, M., Stocchi, F., Testa, S. R., De Pandis, F., and Agnoli, A. (1991). Alterations of thermoregulation in Parkinson's disease. Funct. Neurol. 6, 279-283.
Dodd, S. L., Hain, B., Senf, S. M., and Judge, A. R. (2009). Hsp27 inhibits IKKbeta-induced NF-kappaB activity and skeletal muscle atrophy. FASEB J. 23, 3415-3423. doi: 10.1096/fj.08-124602

Dorsey, E. R., Elbaz, A., Nichols, E., Abd-Allah, F., Abdelalim, A., Adsuar, J. C., et al. (2018). Global, regional, and national burden of Parkinson's disease, 19902016: a systematic analysis for the global burden of disease study 2016. Lancet Neurol. 17, 939-953.

Ely, B. R., Clayton, Z. S., McCurdy, C. E., Pfeiffer, J., Needham, K. W., Comrada, L. N., et al. (2019). Heat therapy improves glucose tolerance and adipose tissue insulin signaling in polycystic ovary syndrome. Am. J. Physiol. Endocrinol. Metab. 317, E172-E182. doi: 10.1152/ajpendo.00549.2018

Evans, C. G., Wisen, S., and Gestwicki, J. E. (2006). Heat shock proteins 70 and 90 inhibit early stages of amyloid beta-(1-42) aggregation in vitro. J. Biol. Chem. 281, 33182-33191.

Evens, A., and Clark, C. (2017). Does assisted cycling improve function in those with Parkinson's disease? Phys. Ther. Rev. 22, 243-253.

Faulkner, S. H., Jackson, S., Fatania, G., and Leicht, C. A. (2017). The effect of passive heating on heat shock protein 70 and interleukin-6: a possible treatment tool for metabolic diseases? Temperature 4, 292-304. doi: 10.1080/23328940. 2017.1288688

Findley, L. J. (2007). The economic impact of Parkinson's disease. Parkinsonism Relat. Disord. 13, S8-S12.

Fontaine, S. N., Martin, M. D., and Dickey, C. A. (2016). Neurodegeneration and the heat shock protein 70 machinery: implications for therapeutic development. Curr. Top. Med. Chem. 16, 2741-2752.

Frazer, A. K., Pearce, A. J., Howatson, G., Thomas, K., Goodall, S., and Kidgell, D. J. (2018). Determining the potential sites of neural adaptation to cross-education: implications for the cross-education of muscle strength. Eur. J. Appl. Physiol. 118, 1751-1772. doi: 10.1007/s00421-018-3937-5

Galton, C. J., Patterson, K., Xuereb, J. H., and Hodges, J. R. (2000). Atypical and typical presentations of Alzheimer's disease: a clinical, neuropsychological, neuroimaging and pathological study of 13 cases. Brain 123, 484-498.

Gao, X., Carroni, M., Nussbaum-Krammer, C., Mogk, A., Nillegoda, N. B., Szlachcic, A., et al. (2015). Human Hsp70 disaggregase reverses parkinson'slinked alpha-synuclein Amyloid fibrils. Mol. Cell 59, 781-793. doi: 10.1016/j. molcel.2015.07.012

Gibson, O. R., Dennis, A., Parfitt, T., Taylor, L., Watt, P. W., and Maxwell, N. S. (2014). Extracellular Hsp72 concentration relates to a minimum endogenous criteria during acute exercise-heat exposure. Cell Stress Chaperones 19, 389-400. doi: 10.1007/s12192-013-0468-1

Gibson, O. R., Mee, J. A., Taylor, L., Tuttle, J. A., Watt, P. W., Maxwell, N. S., et al. (2015a). Isothermic and fixed-intensity heat acclimation methods elicit equal increases in Hsp72 mRNA. Scand. J. Med. Sci. Sports 25, 259-268. doi: $10.1111 / \mathrm{sms} .12430$

Gibson, O. R., Turner, G., Tuttle, J. A., Taylor, L., Watt, P. W., and Maxwell, N. S. (2015b). Heat acclimation attenuates physiological strain and the HSP72, but not HSP90 $\alpha$, mRNA response to acute normobaric hypoxia. J. Appl. Physiol. 119, 889-899. doi: 10.1152/japplphysiol.00332.2015

Gibson, O. R., Tuttle, J. A., Watt, P. W., Maxwell, N. S., and Taylor, L. (2016). Hsp72 and Hsp90 $\alpha$ mRNA transcription is characterised by large, sustained changes in core temperature during heat acclimation. Cell Stress Chaperones 21, 1021-1035.

Goto, K., Honda, M., Kobayashi, T., Uehara, K., Kojima, A., Akema, T., et al. (2004). Heat stress facilitates the recovery of atrophied soleus muscle in rat. JPN J. Physiol. 54, 285-293.

Goto, K., Oda, H., Kondo, H., Igaki, M., Suzuki, A., Tsuchiya, S., et al. (2011). Responses of muscle mass, strength and gene transcripts to long-term heat stress in healthy human subjects. Eur. J. Appl. Physiol. 111, 17-27. doi: 10.1007/ s00421-010-1617-1

Gubbay, S. S., Kahana, E., Zilber, N., Cooper, G., Pintov, S., and Leibowitz, Y. (1985). Amyotrophic lateral sclerosis. A study of its presentation and prognosis. J. Neurol. 232, 295-300.

Hafen, P. S., Abbott, K., Bowden, J., Lopiano, R., Hancock, C. R., and Hyldahl, R. D. (2019). Daily heat treatment maintains mitochondrial function and attenuates atrophy in human skeletal muscle subjected to immobilization. J. Appl. Physiol. 127, 47-57. doi: 10.1152/japplphysiol.01098.2018

Hafen, P. S., Preece, C. N., Sorensen, J. R., Hancock, C. R., and Hyldahl, R. D. (2018). Repeated exposure to heat stress induces mitochondrial adaptation 
in human skeletal muscle. J. Appl. Physiol. 125, 1447-1455. doi: 10.1152/ japplphysiol.00383.2018

Hass, C. J., Collins, M. A., and Juncos, J. L. (2007). Resistance training with creatine monohydrate improves upper-body strength in patients with Parkinson disease: a randomized trial. Neurorehabil. Neural Repair. 21, 107-115.

Heinonen, I., and Laukkanen, J. A. (2018). Effects of heat and cold on health, with special reference to Finnish sauna bathing. Am. J. Physiol. Regul. Integr. Comp. Physiol. 314, R629-R638. doi: 10.1152/ajpregu.00115.2017

Hendy, A. M., and Lamon, S. (2017). The cross-education phenomenon: brain and beyond. Front. Physiol. 8:297. doi: 10.3389/fphys.2017.00297

Hesketh, K., Shepherd, S. O., Strauss, J. A., Low, D. A., Cooper, R. G., Wagenmakers, A. J. M., et al. (2019). Passive heat therapy in sedentary humans increases skeletal muscle Capillarisation and eNOS content but not mitochondrial density or GLUT4 content. Am. J. Physiol. Heart Circ. Physiol. 317, H114-H123.

Hoekstra, S. P., Bishop, N. C., Faulkner, S. H., Bailey, S. J., and Leicht, C. A. (2018). The acute and chronic effects of hot water immersion on inflammation and metabolism in sedentary, overweight adults. J. Appl. Physiol. 125, 2008-2018. doi: 10.1152/japplphysiol.00407.2018

Hoffmann, T. C., Maher, C. G., Briffa, T., Sherrington, C., Bennell, K., Alison, J., et al. (2016). Prescribing exercise interventions for patients with chronic conditions. CMAJ 188, 510-518.

Hom, L. L., Lee, E. C.-H., Apicella, J. M., Wallace, S. D., Emmanuel, H., Klau, J. F., et al. (2012). Eleven days of moderate exercise and heat exposure induces acclimation without significant HSP70 and apoptosis responses of lymphocytes in college-aged males. Cell Stress Chaperones 17, 29-39. doi: 10.1007/s12192011-0283-5

Hooper, P. L. (1999). Hot-tub therapy for type 2 diabetes mellitus. New Engl. J. Med. $341,924-925$.

Hoshino, T., Nakaya, T., Araki, W., Suzuki, K., Suzuki, T., and Mizushima, T. (2007). Endoplasmic reticulum chaperones inhibit the production of amyloid- $\beta$ peptides. Biochem. J. 402, 581-589.

Hou, L., Chen, W., Liu, X., Qiao, D., and Zhou, F. M. (2017). Exercise-induced neuroprotection of the nigrostriatal dopamine system in Parkinson's disease. Front. Aging Neurosci. 9:358. doi: 10.3389/fnagi.2017.00358

Janssen, C. W., Lowry, C. A., Mehl, M. R., Allen, J. J., Kelly, K. L., Gartner, D. E., et al. (2016). Whole-body hyperthermia for the treatment of major depressive disorder: a randomized clinical trial. JAMA Psychiat. 73, 789-795. doi: 10.1001/jamapsychiatry.2016.1031

Jinwal, U. K., Miyata, Y., Koren, J., Jones, J. R., Trotter, J. H., Chang, L., et al. (2009). Chemical manipulation of Hsp70 ATPase activity regulates Tau stability. J. Neurosci. 29, 12079-12088. doi: 10.1523/JNEUROSCI.3345-09.2009

Kalmar, B., Edet-Amana, E., and Greensmith, L. (2012). Treatment with a coinducer of the heat shock response delays muscle denervation in the SOD1G93A mouse model of amyotrophic lateral sclerosis. Amyotroph. Lateral Scler. 13, 378-392. doi: 10.3109/17482968.2012.660953

Kalmar, B., Lu, C. H., and Greensmith, L. (2014). The role of heat shock proteins in amyotrophic lateral sclerosis: the therapeutic potential of Arimoclomol. Pharmacol. Ther. 141, 40-54. doi: 10.1016/j.pharmthera.2013.08.003

Kalmar, B., Novoselov, S., Gray, A., Cheetham, M. E., Margulis, B., and Greensmith, L. (2008). Late stage treatment with arimoclomol delays disease progression and prevents protein aggregation in the SOD1G93A mouse model of ALS. J. Neurochem. 107, 339-350.

Kampinga, H. H., and Bergink, S. (2016). Heat shock proteins as potential targets for protective strategies in neurodegeneration. Lancet Neurol. 15, 748-759. doi: 10.1016/S1474-4422(16)00099-5

Kampinga, H. H., Hageman, J., Vos, M. J., Kubota, H., Tanguay, R. M., Bruford, E. A., et al. (2009). Guidelines for the nomenclature of the human heat shock proteins. Cell Stress Chaperones 14, 105-111. doi: 10.1007/s12192-008-0068-7

Kerr, G. K., Worringham, C. J., Cole, M. H., Lacherez, P. F., Wood, J. M., and Silburn, P. A. (2010). Predictors of future falls in Parkinson disease. Neurology 75, 116-124. doi: 10.1212/WNL.0b013e3181e7b688

Kieran, D., Kalmar, B., Dick, J. R., Riddoch-Contreras, J., Burnstock, G., and Greensmith, L. (2004). Treatment with arimoclomol, a coinducer of heat shock proteins, delays disease progression in ALS mice. Nat. Med. 10, 402-405.

Kiernan, M. C., Vucic, S., Cheah, B. C., Turner, M. R., Eisen, A., Hardiman, O., et al. (2011). Amyotrophic lateral sclerosis. Lancet 377, 942-955. doi: 10.1016/ S0140-6736(10)61156-7
Kihara, T., Biro, S., Imamura, M., Yoshifuku, S., Takasaki, K., Ikeda, Y., et al. (2002). Repeated sauna treatment improves vascular endothelial and cardiac function in patients with chronic heart failure. J. Am. Coll. Cardiol. 39, 754-759.

Kimball, A. L., McCue, P. M., Petrie, M. A., and Shields, R. K. (2018). Whole body heat exposure modulates acute glucose metabolism. Int. J. Hyperther. 35 , 644-651. doi: 10.1080/02656736.2018.1516303

Klaips, C. L., Jayaraj, G. G., and Hartl, F. U. (2018). Pathways of cellular proteostasis in aging and disease. J. Cell Biol. 217, 51-63.

Klucken, J., Shin, Y., Masliah, E., Hyman, B. T., and McLean, P. J. (2004). Hsp70 reduces alpha-synuclein aggregation and toxicity. J. Biol. Chem. 279, 25497-25502.

Kodesh, E., and Horowitz, M. (2010). Soleus adaptation to combined exercise and heat acclimation: physiogenomic aspects. Med. Sci. Sports Exerc. 42, 943-952. doi: 10.1249/MSS.0b013e3181c3ac3f

Kojima, A., Goto, K., Morioka, S., Naito, T., Akema, T., Fujiya, H., et al. (2007). Heat stress facilitates the regeneration of injured skeletal muscle in rats. J. Orthop. Sci. 12, 74-82.

Kregel, K. C. (2002). Heat shock proteins: modifying factors in physiological stress responses and acquired thermotolerance. J. Appl. Physiol. 92, 2177-2186.

Kudva, Y. C., Hiddinga, H. J., Butler, P. C., Mueske, C. S., and Eberhardt, N. L. (1997). Small heat shock proteins inhibit in vitro A beta(1-42) amyloidogenesis. FEBS Lett. 416, 117-121.

Kuhlenhoelter, A. M., Kim, K., Neff, D., Nie, Y., Blaize, A. N., Wong, B. J., et al. (2016). Heat therapy promotes the expression of angiogenic regulators in human skeletal muscle. Am. J. Physiol. Regul. Integr. Comp. Physiol. 311, R377-R391. doi: 10.1152/ajpregu.00134.2016

Kulathingal, J., Ko, L.-W., Cusack, B., and Yen, S.-H. (2009). Proteomic profiling of phosphoproteins and glycoproteins responsive to wild-type alpha-synuclein accumulation and aggregation. Biochim. Biophys. Acta Prot. Proteom. 1794, 211-224. doi: 10.1016/j.bbapap.2008.09.025

Labbadia, J., and Morimoto, R. I. (2015). The biology of proteostasis in aging and disease. Ann. Rev. Biochem. 84, 435-464. doi: 10.1146/annurev-biochem060614-033955

Lackie, R. E., Maciejewski, A., Ostapchenko, V. G., Marques-Lopes, J., Choy, W.Y., Duennwald, M. L., et al. (2017). The Hsp70/Hsp90 chaperone machinery in neurodegenerative diseases. Front. Neurosci. 11:254. doi: 10.3389/fnins.2017. 00254

Larson, E. B., Wang, L., Bowen, J. D., McCormick, W. C., Teri, L., Crane, P., et al. (2006). Exercise is associated with reduced risk for incident dementia among persons 65 years of age and older. Ann. Int. Med. 144, 73-81.

Laukkanen, T., Kunutsor, S., Kauhanen, J., and Laukkanen, J. A. (2017). Sauna bathing is inversely associated with dementia and Alzheimer's disease in middle-aged Finnish men. Age Ageing 46, 245-249. doi: 10.1093/ageing/afw212

Leak, R. K. (2014). Heat shock proteins in neurodegenerative disorders and aging. J. Cell Commun. Signal. 8, 293-310.

LeDoux, M. S. (2013). Thermoregulatory dysfunction in Parkinson's Disease. Curr. Clin. Neurol. 24, 213-227.

Lee, M., and Carroll, T. J. (2007). Cross education: possible mechanisms for the contralateral effects of unilateral resistance training. Sports Med. 37, 1-14.

Lee, S., Carson, K., Rice-Ficht, A., and Good, T. (2005). Hsp20, a novel -crystallin, prevents A fibril formation and toxicity. Protein Sci. 14, 593-601.

Leeuwis, A. E., Benedictus, M. R., Kuijer, J. P. A., Binnewijzend, M. A. A., Hooghiemstra, A. M., Verfaillie, S. C. J., et al. (2017). Lower cerebral blood flow is associated with impairment in multiple cognitive domains in Alzheimer's disease. Alzheimer Dement. 13, 531-540. doi: 10.1016/j.jalz.2016.08.013

Littmann, A. E., and Shields, R. K. (2016). Whole body heat stress increases motor cortical excitability and skill acquisition in humans. Clin. Neurophysiol. 127, 1521-1529. doi: 10.1016/j.clinph.2015.11.001

Liu, Y., Yan, T., Chu, J. M.-T., Chen, Y., Dunnett, S., Ho, Y.-S., et al. (2019). The beneficial effects of physical exercise in the brain and related pathophysiological mechanisms in neurodegenerative diseases. Lab. Invest. 99, 943-957. doi: 10. 1038/s41374-019-0232-y

Loprinzi, P. D., Herod, S. M., Cardinal, B. J., and Noakes, T. D. (2013). Physical activity and the brain: a review of this dynamic, bi-directional relationship. Brain Res. 1539, 95-104. doi: 10.1016/j.brainres.2013.10.004

Luo, W., Dou, F., Rodina, A., Chip, S., Kim, J., Zhao, Q., et al. (2007). Roles of heat-shock protein 90 in maintaining and facilitating the neurodegenerative phenotype in tauopathies. Proc. Natl. Acad. Sci. 104, 9511-9516. 
Luo, W., Sun, W., Taldone, T., Rodina, A., and Chiosis, G. (2010). Heat shock protein 90 in neurodegenerative diseases. Mol. Neurodegen. 5:24. doi: 10.1186/ 1750-1326-5-24

Maeda, T., Mimori, K., Suzuki, S., Horiuchi, T., and Makino, N. (2018). Preventive and promotive effects of habitual hot spa-bathing on the elderly in Japan. Sci. Rep. 8:133. doi: 10.1038/s41598-017-18488-3

Magalhães, F. D. C., Amorim, F. T., Passos, R. L. F., Fonseca, M. A., Oliveira, K. P. M., Lima, M. R. M., et al. (2010). Heat and exercise acclimation increases intracellular levels of Hsp72 and inhibits exercise-induced increase in intracellular and plasma Hsp72 in humans. Cell Stress Chaperones 15, 885-895. doi: 10.1007/s12192-010-0197-7

Maley, M. J., Hunt, A. P., Stewart, I. B., Faulkner, S. H., and Minett, G. M. (2019). Passive heating and glycaemic control in non-diabetic and diabetic individuals: a systematic review and meta-analysis. PLoS One 14:e0214223. doi: 10.1371/ journal.pone.0214223

Maloyan, A., Eli-berchoer, L., Semenza, G. L., Gerstenblith, G., Stern, M. D., Horowitz, M., et al. (2005). HIF-1alpha-targeted pathways are activated by heat acclimation and contribute to acclimation-ischemic cross-tolerance in the heart. Physiol. Genom. 23, 79-88.

Maloyan, A., Palmon, A., Horowitz, M., Tetievsky, A., Cohen, O., Eli-berchoer, L., et al. (2011). Heat acclimation increases the basal HSP72 level and alters its production dynamics during heat stress memory. Am. J. Physiol. 276, R1506-R1515.

Mandel, S., Grunblatt, E., Riederer, P., Amariglio, N., Jacob-Hirsch, J., Rechavi, G., et al. (2005). Gene expression profiling of sporadic Parkinson's Disease substantia nigra pars compacta reveals impairment of ubiquitin-proteasome subunits, skpla, aldehyde dehydrogenase, and chaperone HSC-70. Ann. N. Y. Acad. Sci. 1053, 356-375.

Martyr, A., Nelis, S. M., Quinn, C., Rusted, J. M., Morris, R. G., and Clare, L. (2019). The relationship between perceived functional difficulties and the ability to live well with mild-to-moderate dementia: Findings from the IDEAL programme. Int. J. Geriatr. Psychiatr. 34, 1251-1261. doi: 10.1002/gps.5128

McClung, J. P., Hasday, J. D., He, J.-R. R., Montain, S. J., Cheuvront, S. N., Sawka, M. N., et al. (2008). Exercise-heat acclimation in humans alters baseline levels and ex vivo heat inducibility of HSP72 and HSP90 in peripheral blood mononuclear cells. Am. J. Physiol. 294, R185-R191.

McGorm, H., Roberts, L. A., Coombes, J. S., and Peake, J. M. (2018). Turning up the heat: an evaluation of the evidence for heating to promote exercise recovery, muscle rehabilitation and adaptation. Sports Med. 48, 1311-1328. doi: 10.1007/s40279-018-0876-6

Mee, J. A., Gibson, O. R., Tuttle, J. A., Taylor, L., Watt, P. W., Doust, J., et al. (2016). Leukocyte Hsp72 mRNA transcription does not differ between males and females during heat acclimation. Temperature 3, 549-556. doi: 10.1080/ 23328940.2016.1214336

Melzer, T. R., Watts, R., MacAskill, M. R., Pearson, J. F., Rueger, S., Pitcher, T. L., et al. (2011). Arterial spin labelling reveals an abnormal cerebral perfusion pattern in Parkinson's disease. Brain 134, 845-855. doi: 10.1093/brain/awq377

Mero, A., Tornberg, J., Mantykoski, M., and Puurtinen, R. (2015). Effects of farinfrared sauna bathing on recovery from strength and endurance training sessions in men. Springerplus 4:321. doi: 10.1186/s40064-015-1093-5

Montine, T. J., Phelps, C. H., Beach, T. G., Bigio, E. H., Cairns, N. J., Dickson, D. W., et al. (2012). National Institute on Aging-Alzheimer's association guidelines for the neuropathologic assessment of Alzheimer's disease: a practical approach. Acta Neuropathol. 123, 1-11. doi: 10.1007/s00401-011-0910-3

Morrison, S., Sleivert, G. G., and Cheung, S. S. (2004). Passive hyperthermia reduces voluntary activation and isometric force production. Eur. J. Appl. Physiol. 91, 729-736.

Morton, J. P., Maclaren, D. P. M., Cable, N. T., Campbell, I. T., Evans, L., Bongers, T., et al. (2007). Elevated core and muscle temperature to levels comparable to exercise do not increase heat shock protein content of skeletal muscle of physically active men. Acta Physiol. 190, 319-327.

Muchowski, P. J., Schaffar, G., Sittler, A., Wanker, E. E., Hayer-Hartl, M. K., and Hartl, F. U. (2000). Hsp70 and hsp40 chaperones can inhibit self-assembly of polyglutamine proteins into amyloid-like fibrils. Proc. Natl. Acad. Sci. U.S.A. 97, 7841-7846.

Munsat, T. L., Andres, P. L., Finison, L., Conlon, T., and Thibodeau, L. (1988). The natural history of motoneuron loss in amyotrophic lateral sclerosis. Neurology 38:409.
Naito, H., Powers, S. K., Demirel, H. A., Sugiura, T., Dodd, S. L., and Aoki, J. (2000). Heat stress attenuates skeletal muscle atrophy in hindlimb-unweighted rats. J. Appl. Physiol. 88, 359-363.

Nakata, H., Oshiro, M., Namba, M., and Shibasaki, M. (2015). Effects of passive heat stress on human somatosensory processing. Am. J. Physiol. Regul. Integr. Comp. Physiol. 309, R1387-R1396. doi: 10.1152/ajpregu.00280. 2015

Neff, D., Kuhlenhoelter, A. M., Lin, C., Wong, B. J., Motaganahalli, R. L., and Roseguini, B. T. (2016). Thermotherapy reduces blood pressure and circulating endothelin-1 concentration and enhances leg blood flow in patients with symptomatic peripheral artery disease. Am. J. Physiol. Regul. Integr. Comp. Physiol. 311, R392-R400. doi: 10.1152/ajpregu.00147.2016

Nichols, E., Szoeke, C. E. I., Vollset, S. E., Abbasi, N., Abd-Allah, F., Abdela, J., et al. (2019). Global, regional, and national burden of Alzheimer's disease and other dementias, 1990-2016: a systematic analysis for the global burden of disease study 2016. Lancet Neurol. 18, 88-106.

Nosaka, K., Muthalib, M., Lavender, A., and Laursen, P. B. (2007). Attenuation of muscle damage by preconditioning with muscle hyperthermia 1-day prior to eccentric exercise. Eur. J. Appl. Physiol. 99, 183-192.

Oehler, R., Pusch, E., Zellner, M., Dungel, P., Hergovics, N., Homoncik, M., et al. (2001). Cell type-specific variations in the induction of hsp70 in human leukocytes by feverlike whole body hyperthermia. Cell Stress Chaperones 6, 306-315.

Ohno, Y., Yamada, S., Sugiura, T., Ohira, Y., Yoshioka, T., and Goto, K. (2010). A possible role of NF-kappaB and HSP72 in skeletal muscle hypertrophy induced by heat stress in rats. Gen. Physiol. Biophys. 29, 234-242.

Ohori, T., Nozawa, T., Ihori, H., Shida, T., Sobajima, M., Matsuki, A., et al. (2012). Effect of repeated sauna treatment on exercise tolerance and endothelial function in patients with chronic heart failure. Am. J. Cardiol. 109, 100-104. doi: 10.1016/j.amjcard.2011.08.014

Oishi, Y., Hayashida, M., Tsukiashi, S., Taniguchi, K., Kami, K., Roy, R. R., et al. (2009). Heat stress increases myonuclear number and fiber size via satellite cell activation in rat regenerating soleus fibers. J. Appl. 107, 1612-1621. doi: 10.1152/japplphysiol.91651.2008

Paillard, T., Rolland, Y., and de Souto Barreto, P. (2015). Protective effects of physical exercise in Alzheimer's disease and Parkinson's Disease: a narrative review. J. Clin. Neurol. 11, 212-219. doi: 10.3988/jcn.2015.11.3.212

Périard, J. D., Ruell, P., Caillaud, C., and Thompson, M. W. (2012). Plasma Hsp72 (HSPA1A) and Hsp27 (HSPB1) expression under heat stress: influence of exercise intensity. Cell Stress Chaperones 17, 375-383. doi: 10.1007/s12192011-0313-3

Petroni, M. L., Albani, G., Bicchiega, V., Baudo, S., Vinci, C., Montesano, A., et al. (2003). Body composition in advanced-stageParkinson's disease. Acta Diabetol. 40, S187-S190.

Pickering, R. M., Grimbergen, Y. A., Rigney, U., Ashburn, A., Mazibrada, G., Wood, B., et al. (2007). A meta-analysis of six prospective studies of falling in Parkinson's disease. Mov. Disord. 22, 1892-1900.

Pitkala, K. H., Poysti, M. M., Laakkonen, M. L., Tilvis, R. S., Savikko, N., Kautiainen, H., et al. (2013). Effects of the finnish Alzheimer disease exercise trial (FINALEX): a randomized controlled trial. JAMA Int. Med. 173, 894-901.

Politis, M., Wu, K., Molloy, S. G., Bain, P., Chaudhuri, K. R., and Piccini, P. (2010). Parkinson's disease symptoms: the patient's perspective. Mov. Disord. 25, 1646-1651. doi: 10.1002/mds.23135

Prince, M., Bryce, R., Albanese, E., Wimo, A., Ribeiro, W., and Ferri, C. P. (2013). The global prevalence of dementia: a systematic review and metaanalysis. Alzheimer Dement. 9, 63-75.

Pringsheim, T., Jette, N., Frolkis, A., and Steeves, T. D. L. (2014). The prevalence of Parkinson's disease: a systematic review and meta-analysis. Mov. Disord. 29, 1583-1590.

Racinais, S., Wilson, M. G., and Periard, J. D. (2017). Passive heat acclimation improves skeletal muscle contractility in humans. Am. J. Physiol. Regul. Integr. Comp. Physiol. 312:R101. doi: 10.1152/ajpregu.00431.2016

Ransmayr, G. (2011). Physical, occupational, speech and swallowing therapies and physical exercise in Parkinson's disease. J. Neural Trans. 118, 773-781. doi: 10.1007/s00702-011-0622-9

Rolland, Y., Pillard, F., Klapouszczak, A., Reynish, E., Thomas, D., Andrieu, S., et al. (2007). Exercise program for nursing home residents with Alzheimer's disease: a 1-year randomized, controlled trial. J. Am. Geriatr. Soc. 55, 158-165. 
Ross, E. Z., Cotter, J. D., Wilson, L., Fan, J. L., Lucas, S. J., and Ainslie, P. N. (2012). Cerebrovascular and corticomotor function during progressive passive hyperthermia in humans. J. Appl. Physiol. 112, 748-758. doi: 10.1152/ japplphysiol.00988.2011

Saito, H., and Kogure, K. (1989). Thermal sudomotor deficits in Parkinson's disease. Clin. Neurol. 29, 734-740.

Salgado, S., Williams, N., Kotian, R., and Salgado, M. (2013). An evidence-based exercise regimen for patients with mild to moderate Parkinson's disease. Brain Sci. 3, 87-100. doi: 10.3390/brainsci3010087

Sarge, K. D., Murphy, S. P., and Morimoto, R. I. (1993). Activation of heat shock gene transcription by heat shock factor 1 involves oligomerization, acquisition of DNA-binding activity, and nuclear localization and can occur in the absence of stress. Mol. Cell. Biol. 13, 1392-1407.

Schapira, A. H. V., Olanow, C. W., Greenamyre, J. T., and Bezard, E. (2014). Slowing of neurodegeneration in Parkinson's disease and Huntington's disease: future therapeutic perspectives. Lancet 384, 545-555. doi: 10.1016/S01406736(14)61010-2

Schenkman, M., Moore, C. G., Kohrt, W. M., Hall, D. A., Delitto, A., Comella, C. L., et al. (2018). Effect of high-intensity treadmill exercise on motor symptoms in patients with de novo parkinson disease: a phase 2 randomized clinical trial. JAMA Neurol. 75, 219-226. doi: 10.1001/jamaneurol.2017.3517

Schestatsky, P., Valls-Sole, J., Ehlers, J. A., Rieder, C. R., and Gomes, I. (2006). Hyperhidrosis in Parkinson's disease. Mov. Disord. 21, 1744-1748.

Schlader, Z. J., and Vargas, N. T. (2019). Regulation of body temperature by autonomic and behavioral thermoeffectors. Exerc. Sport Sci. Rev. 47, 116-126. doi: 10.1249/JES.0000000000000180

Selsby, J. T., and Dodd, S. L. (2005). Heat treatment reduces oxidative stress and protects muscle mass during immobilization. Am. J. Physiol. Regul. Integr. Comp. Physiol. 289, R134-R139.

Senard, J. M., Raï, S., Lapeyre-Mestre, M., Brefel, C., Rascol, O., Rascol, A., et al. (1997). Prevalence of orthostatic hypotension in Parkinson's disease. J. Neurol. Neurosurg. Psychiat. 63, 584-589.

Senf, S. M., Dodd, S. L., McClung, J. M., and Judge, A. R. (2008). Hsp70 overexpression inhibits NF-kappaB and Foxo3a transcriptional activities and prevents skeletal muscle atrophy. FASEB J. 22, 3836-3845. doi: 10.1096/fj.08110163

Silva, A. Z. D., and Israel, V. L. (2019). Effects of dual-task aquatic exercises on functional mobility, balance and gait of individuals with Parkinson's disease: a randomized clinical trial with a 3-month follow-up. Complement. Ther. Med. 42, 119-124. doi: 10.1016/j.ctim.2018.10.023

Sittler, A., Lurz, R., Lueder, G., Priller, J., Lehrach, H., Hayer-Hartl, M. K., et al. (2001). Geldanamycin activates a heat shock response and inhibits huntingtin aggregation in a cell culture model of Huntington's disease. Hum. Mol. Genet. 10, 1307-1315.

Sojkova, J., Najjar, S. S., Beason-Held, L. L., Metter, E. J., Davatzikos, C., Kraut, M. A., et al. (2010). Intima-media thickness and regional cerebral blood flow in older adults. Stroke 41, 273-279. doi: 10.1161/STROKEAHA.109.566810

Speelman, A. D., van de Warrenburg, B. P., van Nimwegen, M., Petzinger, G. M., Munneke, M., and Bloem, B. R. (2011). How might physical activity benefit patients with Parkinson disease? Nat. Rev. Neurol. 7, 528-534. doi: 10.1038/ nrneurol.2011.107

Stetler, R. A., Gan, Y., Zhang, W., Liou, A. K., Gao, Y., Cao, G., et al. (2010). Heat shock proteins: cellular and molecular mechanisms in the central nervous system. Prog. Neurobiol. 92, 184-211. doi: 10.1016/j.pneurobio.2010.05.002

Sweeney, M. D., Kisler, K., Montagne, A., Toga, A. W., and Zlokovic, B. V. (2018). The role of brain vasculature in neurodegenerative disorders. Nat. Neurosci. 21, 1318-1331. doi: 10.1038/s41593-018-0234-x

Swinn, L., Schrag, A., Viswanathan, R., Bloem, B. R., Lees, A., and Quinn, N. (2003). Sweating dysfunction in Parkinson's disease. Mov. Disord. 18, 1459-1463.

Syrimi, Z. J., Vojtisek, L., Eliasova, I., Viskova, J., Svatkova, A., Vanicek, J., et al. (2017). Arterial spin labelling detects posterior cortical hypoperfusion in nondemented patients with Parkinson's disease. J. Neural Trans. 124, 551-557. doi: 10.1007/s00702-017-1703-1

Takeuchi, K., Hatade, T., Wakamiya, S., Fujita, N., Arakawa, T., and Miki, A. (2014). Heat stress promotes skeletal muscle regeneration after crush injury in rats. Acta Histochem. 116, 327-334. doi: 10.1016/j.acthis.2013.08.010

Thies, W., and Bleiler, L. (2012). Alzheimer's disease facts and figures. Alzheimer Dement. 2012, 131-168.
Thomas, K. N., van Rij, A. M., Lucas, S. J., Gray, A. R., and Cotter, J. D. (2016). Substantive hemodynamic and thermal strain upon completing lower-limb hot-water immersion; comparisons with treadmill running. Temperature 3 , 286-297.

Thomas, M. M., Cheung, S. S., Elder, G. C., and Sleivert, G. G. (2006). Voluntary muscle activation is impaired by core temperature rather than local muscle temperature. J. Appl. Physiol. 100, 1361-1369.

Tinken, T. M., Thijssen, D. H., Hopkins, N., Black, M. A., Dawson, E. A., Minson, C. T., et al. (2009). Impact of shear rate modulation on vascular function in humans. Hypertension 54, 278-285. doi: 10.1161/HYPERTENSIONAHA.109. 134361

Todd, G., Butler, J. E., Taylor, J. L., and Gandevia, S. C. (2005). Hyperthermia: a failure of the motor cortex and the muscle. J. Physiol. 563, 621-631.

Touchberry, C., Le, T., Richmond, S., Prewitt, M., Beck, D., Carr, D., et al. (2007). Diathermy treatment increases heat shock protein expression in female, but not male skeletal muscle. Eur. J. Appl. Physiol. 102, 319-323.

Touchberry, C. D., Gupte, A. A., Bomhoff, G. L., Graham, Z. A., Geiger, P. C., and Gallagher, P. M. (2012). Acute heat stress prior to downhill running may enhance skeletal muscle remodeling. Cell Stress Chaperones 17, 693-705. doi: 10.1007/s12192-012-0343-5

Tyler, C. J., Reeve, T., Hodges, G. J., and Cheung, S. S. (2016). The effects of heat adaptation on physiology, perception and exercise performance in the heat: a meta-analysis. Sports Med. 46, 1699-1724.

Uehara, K., Goto, K., Kobayashi, T., Kojima, A., Akema, T., Sugiura, T., et al. (2004). Heat-stress enhances proliferative potential in rat soleus muscle. JPN J. Physiol. 54, 263-271.

Uygur, M., Bellumori, M., and Knight, C. A. (2017). Effects of a low-resistance, interval bicycling intervention in Parkinson's Disease. Physiother. Theory Pract. 33, 897-904.

Uygur, M., Bellumori, M., LeNoir, K., Poole, K., Pretzer-Aboff, I., and Knight, C. A. (2015). Immediate effects of high-speed cycling intervals on bradykinesia in Parkinson's disease. Physiother. Theor. Pract. 31, 77-82. doi: 10.3109/09593985. 2014.972530

Vardiman, J. P., Jefferies, L., Touchberry, C., and Gallagher, P. (2013). Intramuscular heating through Fluidotherapy and heat shock protein response. J. Athlet. Train. 48, 353-361. doi: 10.4085/1062-6050-48.2.22

Venturelli, M., Scarsini, R., and Schena, F. (2011). Six-month walking program changes cognitive and ADL performance in patients with Alzheimer. Am. J. Alzheimer Dis. Dement. 26, 381-388. doi: 10.1177/153331751141 8956

Wattmo, C., Minthon, L., and Wallin, ÅK. (2016). Mild versus moderate stages of Alzheimer's disease: three-year outcomes in a routine clinical setting of cholinesterase inhibitor therapy. Alzheimer Res. Ther. 8:7. doi: 10.1186/s13195016-0174-1

Webster, C. P., Smith, E. F., Shaw, P. J., and De Vos, K. J. (2017). Protein homeostasis in amyotrophic lateral sclerosis: therapeutic opportunities? Front. Mol. Neurosci. 10:123. doi: 10.3389/fnmol.2017.00123

Wilhelmus, M. M. M., Boelens, W. C., Otte-Höller, I., Kamps, B., de Waal, R. M. W., and Verbeek, M. M. (2006a). Small heat shock proteins inhibit amyloid- $\beta$ protein aggregation and cerebrovascular amyloid- $\beta$ protein toxicity. Brain Res. $1089,67-78$.

Wilhelmus, M. M. M., Otte-Holler, I., Wesseling, P., de Waal, R. M. W., Boelens, W. C., and Verbeek, M. M. (2006b). Specific association of small heat shock proteins with the pathological hallmarks of Alzheimer's disease brains. Neuropathol. Appl. Neurobiol. 32, 119-130.

Wüllner, U., Schmitz-Hübsch, T., Antony, G., Fimmers, R., Spottke, A., Oertel, W. H., et al. (2007). Autonomic dysfunction in 3414 Parkinson's disease patients enrolled in the German network on Parkinson's disease (KNP e.V.): the effect of ageing. Eur. J. Neurol. 14, 1405-1408.

Xu, J., Zhang, Y., Qiu, C., and Cheng, F. (2017). Global and regional economic costs of dementia: a systematic review. Lancet 390:S47.

Xu, Q., Park, Y., Huang, X., Hollenbeck, A., Blair, A., Schatzkin, A., et al. (2010). Physical activities and future risk of Parkinson disease. Neurology 75, 341-348. doi: 10.1212/WNL.0b013e3181ea1597

Yamada, P. M., Amorim, F. T., Moseley, P., Robergs, R., and Schneider, S. M. (2007). Effect of heat acclimation on heat shock protein 72 and interleukin-10 in humans. J. Appl. Physiol. 103, 1196-1204. 
Yoshihara, T., Naito, H., Kakigi, R., Ichinoseki-Sekine, N., Ogura, Y., Sugiura, T., et al. (2013). Heat stress activates the Akt/mTOR signalling pathway in rat skeletal muscle. Acta Physiol. 207, 416-426. doi: 10.1111/apha.12040

Zarouchlioti, C., Parfitt, D. A., Li, W., Gittings, L. M., and Cheetham, M. E. (2018). DNAJ Proteins in neurodegeneration: essential and protective factors. Philos. Trans. R. Soc. B Biol. Sci. 373:20160534. doi: 10.1098/rstb.2016. 0534

Zheng, Y., Im, C.-N., and Seo, J.-S. (2006). Inhibitory effect of Hsp70 on angiotensin II-induced vascular smooth muscle cell hypertrophy. Exp. Mol. Med. 38, 509-518.
Conflict of Interest: The authors declare that the research was conducted in the absence of any commercial or financial relationships that could be construed as a potential conflict of interest.

Copyright $\odot 2020$ Hunt, Minett, Gibson, Kerr and Stewart. This is an open-access article distributed under the terms of the Creative Commons Attribution License (CC BY). The use, distribution or reproduction in other forums is permitted, provided the original author(s) and the copyright owner(s) are credited and that the original publication in this journal is cited, in accordance with accepted academic practice. No use, distribution or reproduction is permitted which does not comply with these terms. 